\title{
Azithromycin Has Lung Barrier Protective Effects in a Cell Model Mimicking Ventilator-Induced Lung Injury
}

\author{
Jon P. Joelsson 1,2, Iwona T. Myszor ${ }^{3}$, Snaevar Sigurdsson', Fredrik Lehmann ${ }^{4}$, Clive P. Page 4,5, \\ Gudmundur H. Gudmundsson ${ }^{3}$, Thorarinn Gudjonsson 1,2 and Sigurbergur Karason 1,6 \\ ${ }^{1}$ Stem Cell Research Unit, BioMedical Center, School of Health Sciences, University of Iceland, Reykjavík, Iceland; ${ }^{2}$ Department of Laboratory \\ Hematology, Landspitali-University Hospital, Reykjavík, Iceland; ${ }^{3}$ Life and Environmental Sciences, BioMedical Center, University of Iceland, Reykjavík, \\ Iceland; ${ }^{4}$ EpiEndo Pharmaceuticals, Reykjavík, Iceland; ${ }^{5}$ Sackler Institute of Pulmonary Pharmacology, King's College London, London, UK; \\ ${ }^{6}$ Landspitali-University Hospital, Intensive Care Unit, Reykjavík, Iceland
}

\begin{abstract}
Azithromycin (AZM) is a broad-spectrum antibiotic widely used to treat infections. AZM also has been shown to have anti-inflammatory and immunomodulatory functions unrelated to its antibacterial activity that contribute to the effectiveness of this drug in chronic respiratory diseases. The mechanisms behind these beneficial effects are not yet fully elucidated. We have previously shown that AZM enhances barrier integrity of bronchial epithelial cells and directs them towards epidermal differentiation.

In this study, we analyzed the effect of AZM pre-treatment of human bronchial and alveolar derived cell lines on mechanical stress in a cyclical pressure air-liquid interface device (CPAD) that models the disruption of the epithelial barrier with increased inflammatory response in lung tissue, which is associated with ventilator-induced lung injury (VILI). Immunostaining and electron microscopy showed that barrier integrity of the epithelium was compromised by cyclically stressing the cells but maintained when cells had been pre-treated with AZM. Lamellar body formation was revealed in AZM pre-treated cells, possibly further supporting the barrier enhancing effects. RNA sequencing showed that the inflammatory response was attenuated by AZM treatment before cyclical stress. YKL-40, an emerging inflammatory marker, increased both due to cyclical stress and upon AZM treatment. These data confirm the usefulness of the CPAD to model ventilator-induced lung injury and suggest that $A Z M$ has barrier protective and immunomodulatory effects, attenuating the inflammatory response during mechanical stress, and might therefore be lung protective during mechanical ventilation. The model could be used to assess further drug candidates that influence barrier integrity and modulate inflammatory response.
\end{abstract}

\section{Introduction}

Azithromycin (AZM) is a broad-spectrum macrolide antibiotic used to treat bacterial infections, mainly of the respiratory system. The antibacterial effects of AZM are mediated through binding to the 50S subunit of the bacterial ribosome (Champney and Burdine, 1998; Champney et al., 1998; Hansen et al., 2002). However, there is increasing evidence that AZM has other pharmacological effects beyond its antibacterial activity, as it improves the health of patients suffering from chronic airway diseases such as chronic obstructive lung disease (COPD), bronchitis obliterans (BO), diffuse panbronchiolitis (DPB), asthma and cystic fibrosis (CF) (Gibson et al., 2017; Gotfried, 2004; Kawamura et al., 2017; Naderi et al., 2018; Pomares et al., 2018; Principi et al., 2015; Ramos and Criner, 2014) when used continuously.

Our group has shown that AZM enhances epithelial barrier integrity in air-liquid interface (ALI) cultures and protects against bacterial infections (Asgrimsson et al., 2006; Halldorsson et al., 2010). We have also shown that AZM treatment causes bronchial epithelial cells to differentiate towards an epidermal phenotype, along with forming multivesicular and lamellar bodies, and that saturated lipids conjugate to the AZM molecule when it enters the cell (Arason et al., 2019).
Received January 27, 2020; Accepted May 15, 2020;

Epub May 19, 2020; ¡ The Authors, 2020.

ALTEX 37(4), 545-560. doi:10.14573/altex.2001271

Correspondence: Sigurbergur Kárason, MD, PhD

Landspitali - University Hospital, Department of Anesthesiology

Intensive Care Unit, Hringbraut 101

101 Reykjavík, Iceland

(skarason@landspitali.is)
This is an Open Access article distributed under the terms of the Creative Commons Attribution 4.0 International license (http://creativecommons.org/licenses/by/4.0/) which permits unrestricted use, distribution and reproduction in any medium, provided the original work is appropriately cited. 
Acute respiratory distress syndrome (ARDS) is a serious condition of severe respiratory failure with high mortality commonly encountered amongst critically ill patients in intensive care units (ICUs). ARDS is characterized by alveolar-capillary barrier failure in the distal bronchi and alveoli, and the expansion of resident macrophages that release signals prompting a response from inflammatory cells in the nearby pulmonary vasculature. This is followed by fluid accumulation or a complete collapse of the alveolar sacs, resulting in loss of gas exchange and inadequate aeration (Thompson et al., 2017). During mechanical ventilation (MV), air is forced into the lungs, which can lead to damage of the lung epithelium due to mechanical stress and ultimately, in some cases, ventilator-induced lung injury (VILI) (Slutsky and Ranieri, 2013). MV can therefore exacerbate ARDS by causing further lung injury.

Clinical research on VILI/ARDS is challenging due to the highrisk nature of invasive diagnostic procedures in patients with such severe respiratory failure. Access to patient lung samples is therefore limited, and although there are numerous in vitro stress-inducing lung models (Huh, 2015; Karadottir et al., 2015; Ressler et al., 2000; Shiomi et al., 2011; Yu and Li, 2017; Zhao et al., 2014), they are restricted mimics of events in human lungs during ARDS or VILI because of the cyclical nature of MV.

In a recent paper, we described a device referred to as a cyclical pressure air-liquid interface device (CPAD) (Joelsson et al., 2019) in which cultures of human lung cells cultured at ALI are exposed to cyclical pressure to model MV. This device aims to replace animal experiments on MV and VILI with a human-relevant system that allows mechanistic investigation.

In this work, we use the CPAD to cyclically stress bronchial and alveolar cell lines in ALI cultures and show that, whereas untreated cells present a disrupted phenotype following mechanical strain, AZM maintains the barrier integrity in both cell lines. We observed vesicle and lamellar body formations in CPAD stressed cells which was exaggerated in AZM pre-treated cells. We also show that AZM pre-treatment attenuates the inflammatory response in CPAD stressed cells.

\section{Methods}

\section{Cell culture}

Two cell lines were used in this research. VA10 (Halldorsson et al., 2007) was cultured in animal origin-free Bronchial/Tracheal Epithelial Cell Medium (Cell Applications, 511A-500) supplemented with retinoic acid (Cell Applications, 511-RA), and hAELVi (Kuehn et al., 2016) was cultured in Human Airway Epithelial Cell Medium (InSCREENEX, INS-ME-1013). Both cell lines were supplemented with Penicillin $(20 \mathrm{IU} / \mathrm{mL}) /$ Streptomycin $(20 \mu \mathrm{g} / \mathrm{mL})$ (Life Technologies, 15140122). The cell culture medium used for cell differentiation of VA10 cells in ALI cultures was Dulbecco's Modified Eagle Medium F-12 Nutrient Mixture (DMEM/F12, Thermo Fisher Scientific) which was supplemented with $2 \%$ Ultroser G (PALL). All cell cultures were screened bi-monthly for Mycoplasma contamination by way of Phenol/Chloroform extraction (all negative).

Both cell lines were cultured at the air-liquid interface (ALI) on $12 \mathrm{~mm}$ diameter Transwell ${ }^{\mathrm{TM}}$ filter inserts (Corning $0.4 \mu \mathrm{m}$ ) pre-coated with collagen IV (Sigma, C7521) for the VA10 cell line and huAEC coating solution (InSCREENEX, INS-SU-1018) for the hAELVi cell line. 200.000 cells were seeded per transwell filter. Cell lines were cultured for three weeks with or without $25 \mu \mathrm{g} /$ mLAZM (Zithromax, dissolved in 96\% ethanol).

Trans-epithelial electrical resistance (TEER) was measured every other day. For this, medium was added to the apical side and resistance was measured using a Millicell ERS-2 Volt-Ohm meter.

\section{Cyclical pressure ALI device}

Both cell lines were cultured for 3 weeks with or without AZM supplementation. Half of the wells containing the cell layers were then placed in the CPAD for cyclical stressing for $24 \mathrm{~h}$. The cyclical stress conditions were set according to our previous study (Joelsson et al., 2019) with peak pressure at $27 \mathrm{~cm} \mathrm{H}_{2} \mathrm{O}$ and end-expiratory pressure at $5 \mathrm{~cm} \mathrm{H}_{2} \mathrm{O}$, creating a driving pressure of $22 \mathrm{~cm} \mathrm{H} \mathrm{H}_{2} \mathrm{O}$, with a respiratory rate of 16 breaths/min. The cyclical stress profile used in this study has a pressure difference that would produce ventilator induced lung injury (VILI) in clinical circumstances. For the purposes of clarity, combinations of the following terms are used to describe the treatment conditions: no treatment $=\mathrm{CON}$, Azithromycin pre-treatment $=\mathrm{AZM}$, No stress $=$ Static and $27 \mathrm{~cm} \mathrm{H}_{2} \mathrm{O}$ cyclical stress $=$ Stress.

\section{RNA sequencing and gene expression analysis}

RNA was isolated from cells using TRIzol reagent (Invitrogen, Thermo Fisher Scientific) according to the manufacturer's protocol. RNA sequencing was performed at BGI Genomics. We quantified the RNA transcript expression with Kallisto version 0.45.0 (Bray et al., 2016) using the Ensembl v94 reference transcriptome (Yates et al., 2016). Gene expression estimates were computed with the sleuth R package v0.30 (Pimentel et al., 2017). Gene set enrichment analysis was performed with GSEA software v4.0.1 (Mootha et al., 2003; Subramanian et al., 2005). Pre-ranked gene lists were prepared by ordering the genes by expression difference significance (q-value multiplied with the sign of the logfold change) and tested for enrichment in the MSigDB hallmark gene set collection (Liberzon et al., 2015). Significantly differentially expressed genes were uploaded to PANTHER gene ontology classification system using a statistical overrepresentation test and biological process annotation data set.

All qPCRs were performed as previously reported (Joelsson et al., 2019). Primers used are listed in Tab. $\mathrm{S}^{1}$.

\section{Protein analysis}

$15 \mu \mathrm{g}$ total protein was separated using a NuPAGE 4-12\% BisTris gradient gel (Life Technologies, NP0323). Primary antibodies used: mouse anti-chitinase-3-like protein 1 (YKL-40) (Millipore, MABC196); rabbit anti-IkBa (Cell Signaling Technolo-

\footnotetext{
1 doi:10.14573/altex.2001271s
} 
Fig. 1A: Azithromycin pre-treatment maintains barrier integrity in cyclically stressed VA10 cell layers

Confocal immunofluorescent images of ALI-cultured VA10 cell layers with/without AZM treatment (CON/AZM) in static or stress conditions (Static/Stress) for 21 days. i) Actin stained with phalloidin (green); ii) E-Cadherin (green) and nuclei stained with DAPI (blue). Images are representative of 3 independent experiments $(\mathrm{N}=3)$. Scale bar is $100 \mu \mathrm{m}$. iii) Electron microscopic images of ALIcultured VA10 cell layers with/without AZM treatment (CON/AZM) in static or stress conditions (Static/Stress). Images are representative of 3 independent experiments $(\mathrm{N}=3)$. Scale bars are $10 \mu \mathrm{m}$ for top images, $2 \mu \mathrm{m}$ for middle images and $1 \mu \mathrm{m}$ for lower images.

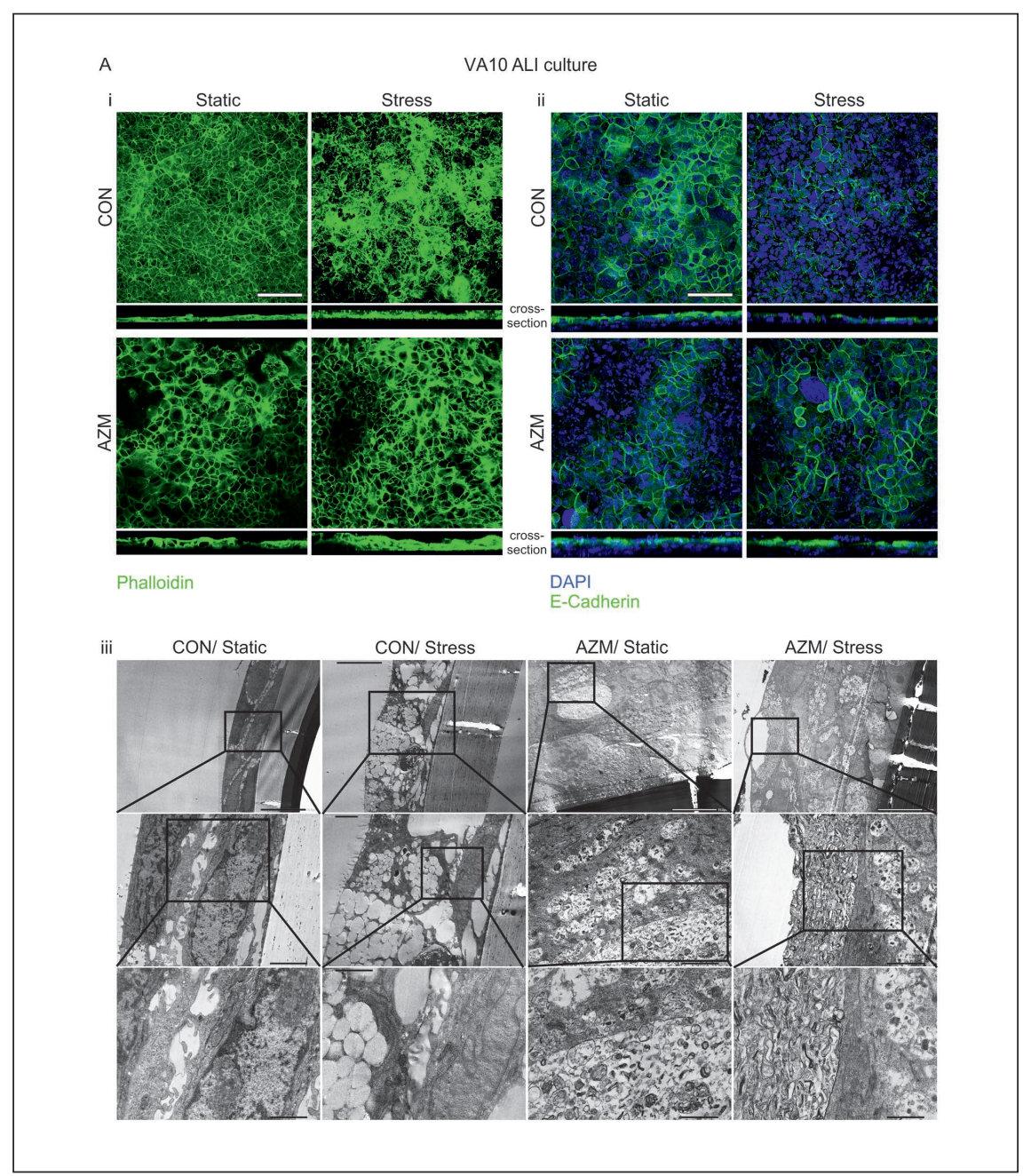

gy, 9242S) and rabbit anti- $\beta$-tubulin (Cell Signaling Technology, 2128 ). Secondary antibodies conjugated with horse radish peroxidase (HRP) (goat anti-rabbit IgG, Sigma, A0545; goat anti-mouse IgG, Millipore, AP181P) were used. Conditioned medium from cell culture was analyzed by sandwich enzyme-linked immunosorbent assays (ELISAs) using an interleukin 8 (IL-8) assay kit (Peprotech, UK).

\section{Confocal imaging}

Samples were fixed in formalin and embedded in paraffin, then sectioned and immunostained. Antibodies used were rabbit anti-NFkB p65 (Santa Cruz Biotechnology, sc-372), mouse anti-E-Cadherin (BD Transduction Laboratories, 610182), mouse anti-chitinase-3-like protein 1 (YKL-40) (Millipore, MAB196), rabbit anti-surfactant protein B (Abcam, ab40876). Appropriate secondary antibodies were purchased from ThermoFisher. Counter staining was done using DAPI (1:5000) (Sigma-Aldrich). Phalloidin (1:40) used for actin staining was from ThermoFisher (A22283). A list of secondary antibodies used is provided in Table S2 ${ }^{1}$. Immunofluorescence was imaged using an Olympus FV1200 confocal microscope (Olympus, Tokyo, Japan). Pixel intensity quantifications were calculated with ImageJ.
Transmission electron microscopy

Cell layers were fixed with $2.5 \%$ glutaraldehyde for $20 \mathrm{~min}$ followed by washing. Cells were dehydrated and then embedded in resin. $100 \mathrm{~nm}$ sections were cut by ultramicrotome. Sections were stained with lead citrate and imaged using a JEM-1400PLUS PL Transmission Electron Microscope.

\section{Statistical analysis}

For determining statistical significance analysis, a two-way ANOVA was utilized and calculated using GraphPad Prism 8.0. Error bars represent the standard deviation (SD).

\section{Results}

\subsection{Azithromycin pre-treatment maintains barrier integrity in cyclically stressed bronchial and alveolar lung epithelial cell lines}

VA10 bronchial cells

VA10 bronchial cell lines exhibited increased TEER when treated with AZM (Fig. S1A ${ }^{1}$ ) as reported previously by (Arason et al., 


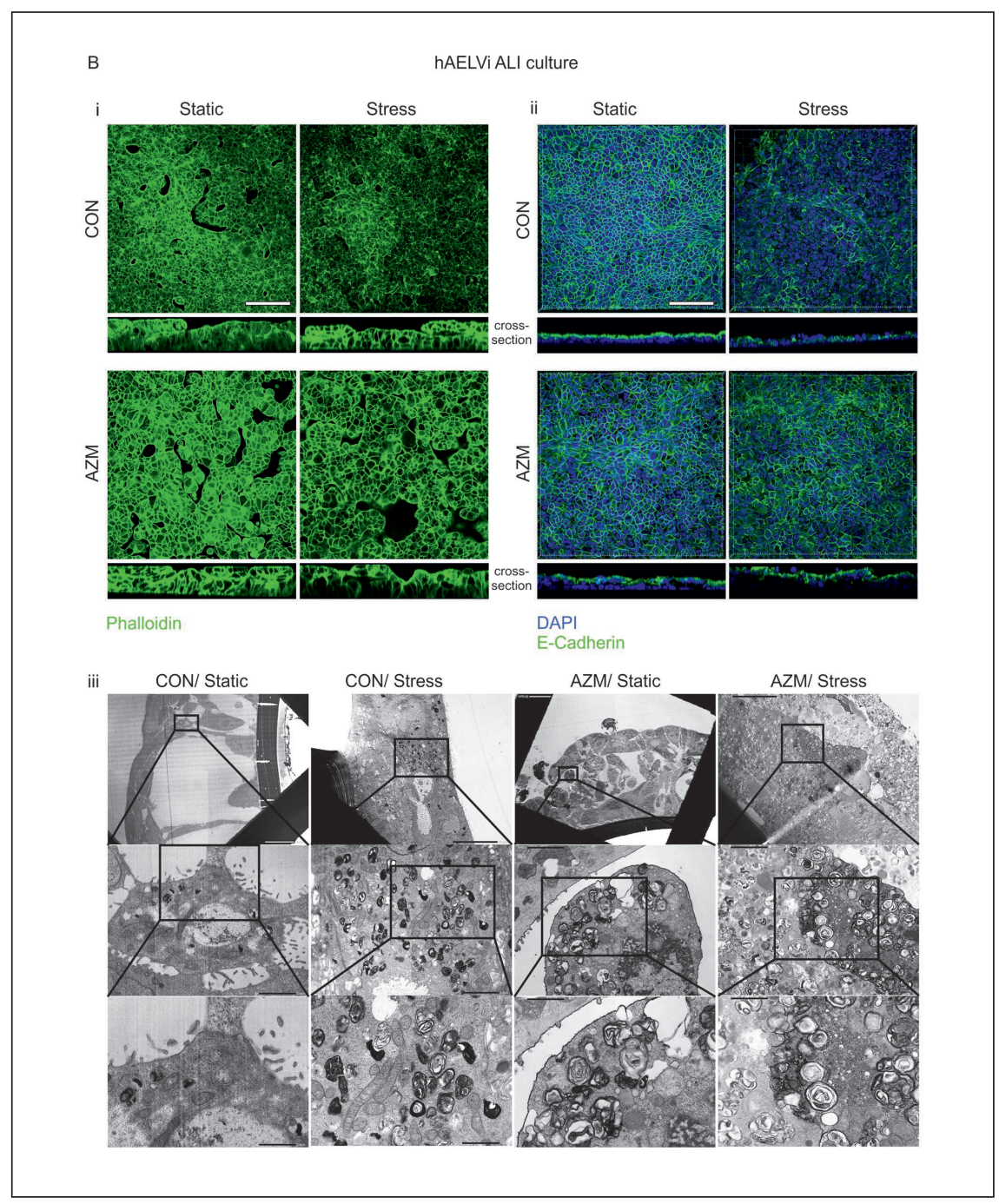

Fig. 1B: Azithromycin pre-treatment maintains barrier integrity in cyclically stressed hAELVi cell layers Confocal immunofluorescent images of ALI-cultured hAELVi cell layers with/ without AZM treatment (CON/AZM) in static or stress conditions (Static/Stress) for 21 days. i) Actin stained with phalloidin (green); ii) E-Cadherin (green) and nuclei stained with DAPI (blue). Images are representative of 3 independent experiments $(\mathrm{N}=3)$. Scale bar is 100 $\mu \mathrm{m}$. iii) Electron microscopic images of ALI-cultured VA10 cell layers with/without AZM treatment (CON/AZM) in static or stress conditions (Static/Stress). Images are representative of 3 independent experiments $(\mathrm{N}=3)$. Scale bars are $10 \mu \mathrm{m}$ for top images, $2 \mu \mathrm{m}$ for middle images and $1 \mu \mathrm{m}$ for lower images.

2019). Actin staining with phalloidin of ALI-cultured VA10 cells displayed a grid-like formation (Fig. 1Ai, upper left). Cyclically stressing VA10 cell layers resulted in a disruption of this structure along with aggregation of actin filaments (Fig. 1Ai, upper right). AZM treatment of VA10 cell layers showed the same grid-like form of the lung epithelial layer as seen in the control cells (Fig. 1Ai, lower left). Importantly, AZM treatment consistently resulted in larger cells, possibly due to changes in lipid metabolism, as seen previously in VA10 cells (Arason et al., 2019). Cyclically stressing AZM pre-treated cell layers maintained this structure without aggregation or disruption of actin (Fig. 1Ai, lower right).

Similar effects were observed when cell layers were stained for E-cadherin: The E-cadherin signal was diminished compared to controls in cyclically stressed cells (CON/Stress), but AZM pre-treatment retained the unstressed control phenotype in both the unstressed (AZM/Static) and cyclically stressed cell layers (AZM/Stress) (Fig. 1Aii).

When viewed in the electron microscope, VA10 ALI cultured cells (CON/Static) presented a polarized uniform cell layer (Fig.
1Aiii). When the cell layer was cyclically stressed (CON/Stress), it started to form vesicles, and a disruption of the polarized uniform phenotype was detected with wider gaps between cells (Fig. 1Aiii) (Joelsson et al., 2019). When the cells were treated with AZM (AZM/Static) for the duration of the ALI culture, the cell layer became thicker (Arason et al., 2019), and vesicles and lamellar bodies (LB) appeared (Fig. 1Aiii). When AZM pre-treated cell layers were stressed (AZM/Stress), the vesicles and LBs along with the thicker layer were observed, but not the disrupted phenotype (Fig. 1Aiii).

\section{hAELVi alveolar cells}

The recently established hAELVi cell line (Kuehn et al., 2016) was used to analyze the effect of AZM treatment and cyclical stress on an alveolar-derived cell line. AZM treatment resulted in no significant difference in TEER measurements (Fig. S1B ${ }^{1}$ ).

Phalloidin-stained hAELVi cell layers viewed by confocal microscopy showed uniform tube-like structures within the cell layer that were reduced with cyclical stress as the structures were 


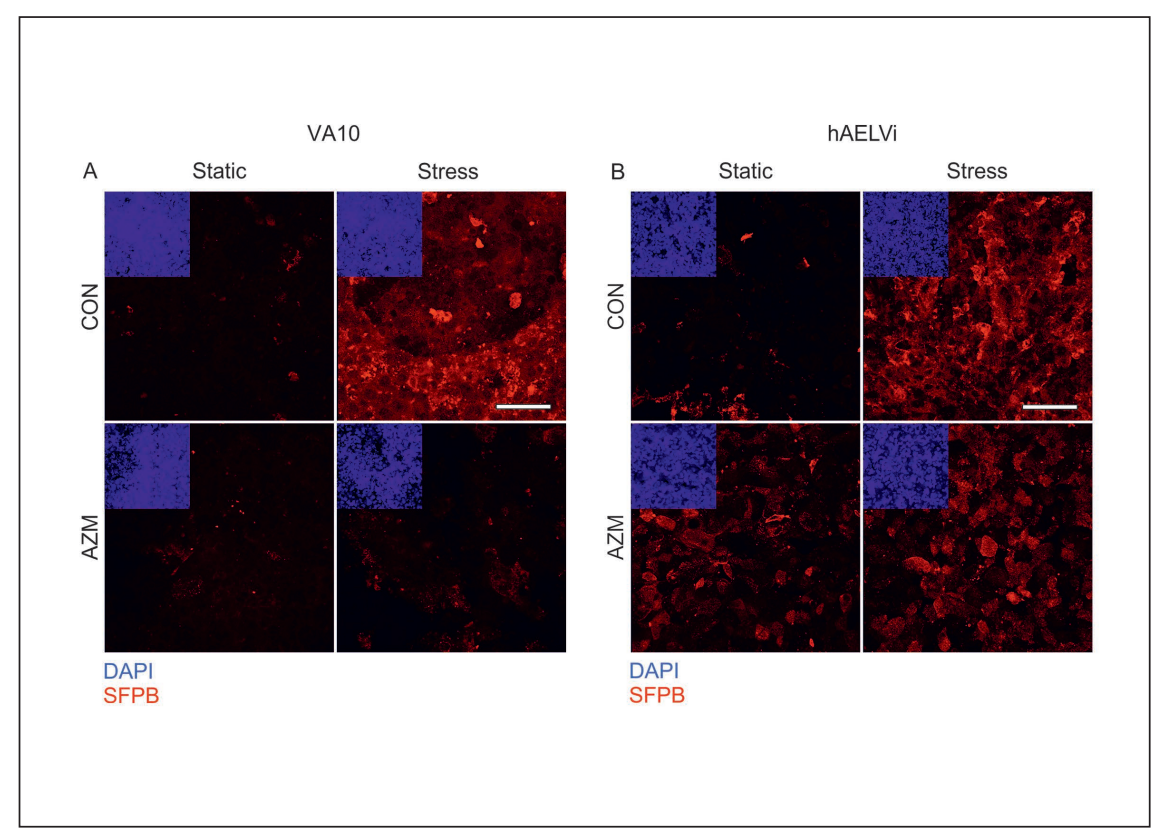

Fig. 2: Mechanically induced expression of surfactant protein $B$ (SFPB) is attenuated in azithromycin pre-treated cell layers

Confocal immunofluorescent images of ALI-cultured A) VA10

and B) hAELVi cell layers with/without AZM treatment

(CON/AZM) in static or stress conditions

(Static/Stress) for 21 days stained for SFPB and nuclei stained with DAPI (insets). Images are representative of 3 independent experiments $(\mathrm{N}=3)$.

compressed (Fig. 1Bi, upper and Fig. 1Biii). AZM pre-treatment of the hAELVi cell line presented a phenotype similar to the untreated counterparts and remained so when cyclically stressed (Fig. 1Bi, lower).

E-Cadherin staining revealed a clear loss of signal in the stressed cells, but grid formation was maintained in AZM pre-treated cells (Fig. 1Bii).

The hollow, tube-like structures of the hAELVi cell layers (CON/Static) were also visible when viewed in the electron microscope (Fig. 1Biii). These structures were more compacted when cells were exposed to cyclical stress (CON/Stress). Furthermore, LBs were more visible in cyclically stressed cells compared to unstressed cells (Fig. 1Biii). AZM treatment of hAELVi cell layers (AZM/Static) resulted in similar tube-like structures as the untreated cell layers, and LBs started forming (Fig. 1Biii). Cyclically stressing AZM pre-treated cell layers (AZM/Stress) flattened the layer and LBs were more prevalent (Fig. 1Biii).

\section{Surfactant production}

To check whether the observed vesicle formation was associated with surfactant production and because of its connection as a VILI/ARDS associated biomarker (Blondonnet et al., 2016; Meyer and Christie, 2013), we stained the cell layers for surfactant protein B (SFPB).

In VA10 cell layers there was a marked increase in SFPB expression under cyclical stress (Fig. 2A, upper). AZM treatment of the VA10 cell layers did not result in a pronounced SFPB increase but interestingly, pre-treating the cell layers with AZM and then cyclically stressing the cells did not result in the noticeable increases in SFPB production seen in the untreated cell layers (Fig. 2A).

The same tests were done on the hAELVi cell line and similar results were seen, with the addition of an increase in SFPB pro- duction by AZM pre-treatment alone, but with no further exacerbations when cyclically stressed (Fig. 2B).

\subsection{AZM attenuates inflammatory response in mechanically stressed VA 10 cell layers - RNA sequencing analysis}

We have previously shown that TNF $\alpha$ and IL8 expression was increased in the CPAD model using bronchial epithelial lung cell lines (Joelsson et al., 2019), and it has been reported that AZM treatment has anti-inflammatory effects in airway epithelial cells (Cigana et al., 2006). Accordingly, we analyzed the effects of AZM treatment on cyclically stressed epithelial cells in the CPAD system. For this purpose, we compared RNA sequenced VA10 cells that had been cultured at ALI for three weeks with or without AZM treatment, then subjected to $27 \mathrm{~cm} \mathrm{H}_{2} \mathrm{O}$ stress for $24 \mathrm{~h}$ in the CPAD or cultured in static conditions.

Running a gene set enrichment analysis (GSEA) (Mootha et al., 2003; Subramanian et al., 2005) on the cells exposed to the two experimental conditions showed that cyclically stressing the untreated cells resulted in considerable enrichment of genes connected to inflammatory-associated gene sets (Fig. 3A). The pathways with the highest normalized enrichment scores (NES) showed significant positive correlation to interferon (IFN) $\alpha$ response, IFN $\gamma$ response, $\mathrm{TNF} \alpha$ signaling via NFKB, inflammatory response, complement system response, and cholesterol homeostasis gene sets (Fig. 3A).

GSEA of AZM pre-treated cells exposed to CPAD stress (AZM/ Stress) compared to CON/Static, however, showed that some different gene sets were involved in the highest NES scores, showing positive correlation with oxidative phosphorylation, cholesterol homeostasis, MTORC signaling, IFNa response, MYC target V1 and protein secretion gene sets (Fig. 3B and Fig. S2 ${ }^{1}$ ). Some pathways, such as the IFN $\alpha$ gene pathway, were enriched in both conditions, but the NES for the inflammation related 
A

\section{CON/ Static vs CON/ Stress Gene sets correlated:}

E $\begin{aligned} & \text { positively } \\ & \text { negatively }\end{aligned}$

HALLMARK_INTERFERON_ALPHA_RESPONSEHALLMARK_INTERFERON_GAMMA_RESPONSE HALLMARK_TNFA_SIGNALING_VIA_NFKB HALLMARK_INFLAMMATORY_RESPONSE HALLMARK_COMPLEMENT HALLMARK_CHOLESTEROL_HOMEOSTASIS HALLMARK_MTORC1_SIGNALING HALLMARK COAGULATION HALLMARK_TGF_BETA_SIGNALINGHALLMARK PROTEIN SECRETIONHALLMARK KRAS SIGNALING UP HALLMARK_APOPTOSIS HALLMARK ANDROGEN RESPONSETHAMLANDOGEN_RESPONSE-

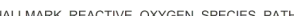
HALLMARK PIIK AKT MTOR SIGNALING HALLMARK ALLOGRAFT REJECTION HALLMARK_IL__STATS_SIGNALING HALLMARK_P53_PATHWAY -

HALLMARK_ESTROGEN_RESPONSE_LATE. HALLMARK HYPOXIA. HALLMARK EPITHELIAL_MESENCHYMAL_TRANSITIONHALLMARK G2M CHECKPOINT HALLMARK_G2M_CHECKPOINTHALLMARKMMC_TARGETS_V1HALLMARK_BILE_ACID_METABOLISM HALLMARK_MYOGENESIS HALLMARK_KRAS_SIGNALING_DN HALLMARK ANGIOGENESIS

HALLMARK_FATTY_ACID_METABOLISM HALLMARK SPERMATOGENESIS HALLMARK_WNT_BETA_CATENIN_SIGNALING HALLMARK_ADIPOGENESISHALLMARK OXIDATIVE PHOSPHORYLATION -



B

\section{CON/ Static vs AZM/ Stress Gene sets correlated}

- $\begin{gathered}\text { positively } \\ \text { negatively }\end{gathered}$
HALLMARK OXIDATIVE PHOSPHORYLATION HALLMARK CHOLESTEROL_HOMEOSTASISHALLMARK_MTORC1_SIGNALING HALLMARK_INTERFERON_ALPHA_RESPONSE-

HALLMARK MYC TARGETS V1.

MALLMARK PROTEIN SECRETION -

HALLMARK_UV_RESPONSE_UP-

HALLMARK_INTERFERON_GAMMA_RESPONSE.

HALLMARK_PI3K_AKT_MTOR_SIGNALING -

HALLMARK_HYPOXIA-

HALLMARK_APOPTOSIS -

HALLMARK ANDROGEN RESPONSE-

HALLMARK ADIPOGENESIS -

HALLMARK TNFA SIGNALING VIA NFKB -

HALLMARK_XENOBIOTIC_METABOLISM -

Ф) HALLMARK_FATTY_ACID_METABOLISM -

HALLMARK P53 PATHWAY -

O.

HALLMARK_INFLAMMATORY_RESPONSE-

HALLMARK_LL2_STAT5_SIGNALING -

HALLMARK_KRAS_SIGNALING_UP.

HALLMARK GLYCOLYSIS -

HALIMARK ESTROGEN RESPONSE_LATE-

HALLMARK_HEME_METABOLISM -

HALLMARK_SPERMATOGENESIS -

HALMARK ESTROGEN RESPONSE EARLY -

HALLMARK APICAL_JUNCTION -

HALLMARK_ANGIOGENESIS.

HALLMARK_KRAS_SIGNALING_DN -

HALLMARK WNT BETA CATENIN SIGNALING -

HALLMARK_NOTCH SIGNALING -

HALLMARK_UV_RESPONSE_DN -

HALLMARK_EPITHELIAL_MESENCHYMAL_TRANSITION-

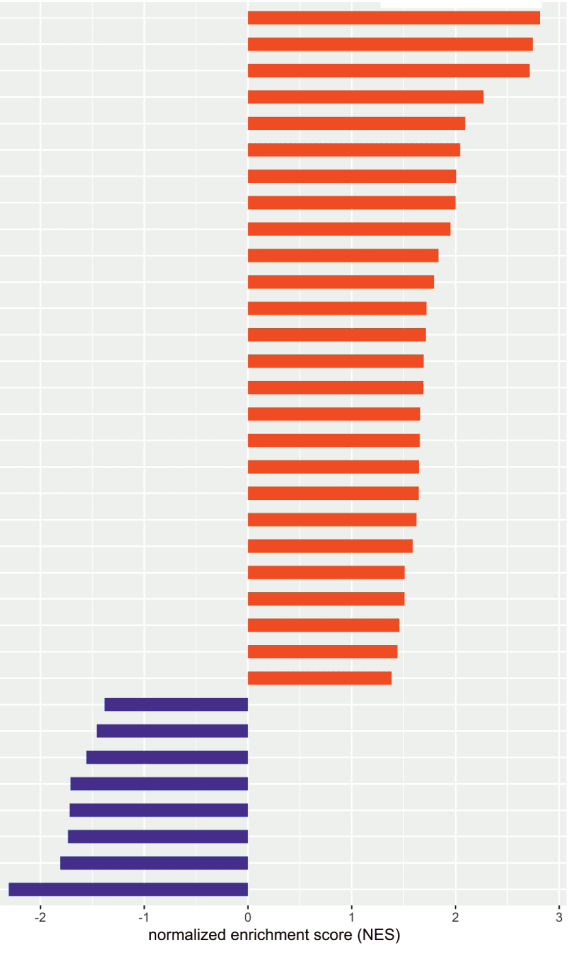

Fig. 3: Pre-treatment with azithromycin results in an attenuated inflammatory response in mechanically stressed VA10 cell layers RNA sequencing analysis Significant (nominal p-value $\leq 0.05$ ) gene set enrichment plots that resulted from comparing conditions are shown:

A) CON/Static vs CON/

Stress;

B) CON/Static vs AZM/

Stress; 
C

\section{CON/ Stress vs AZM/ Stress}

Gene sets correlated positively
nogatively

HALLMARK OXIDATIVE PHOSPHORYLATIONHALMARK CHOLESTEROL HOMEOSTASIS HALUMARK MYC_TARGETS V1. HARMARK_ADPOGENESIS ALLMARK MTORC1 SIGNALING HALLMARK_FATTY ACID_EITABOLISMTARGETSALLMARK SPERMATOGENESIS HALLMARK_HYPOXIAHALLMARK PEROXISOMEHALLMARK_UV_RESPONSE_UPHALLMARK P53 PATHWAY HALLMARK GLYCOLYSIS -

HALLMAPK BIEEACID METABOHSM-

HALLMARK G2M CHECKPOINT -

HALLMARK_G2M_CHECKPOIN -

- hallmank mezMetrabolis WENOBIOTIC_METABOLISM HALLMARK_DNA_REPAIR HALLMARK_MYOGENESIS-
HALLMARK ESTROGEN RESPONSE LATEHALLMARK APOPTOSIS HALLMARK_ANGIOGENESIS-

HALLMARK_HEDGEHOG SIGNALING HALLMARK COMPLEMENT HALLMARK_COAGULATIONHALLMARK_UV_RESPONSE_DN HALLMARK_MITOTIC_SPINDLEHALLMARK ESTROGEN RESPONSE EARLY HALLMARK IL2 STAT5 SIGNALING HALLMARK ALLOGRAFT REJECTION HAUMARK KRAS TOOMUNG

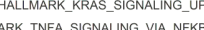

MAR_ HALLMAR_TG_BETA_SIGNALING HALLMARK_N TLAMMATOR_RESPONSEHALLMARK_APICAL_JUNCTIONHALLMARK_INTERFERON_GAMMA_RESPONSE HALLMARK_INTERFERON_ALPHA_RESPONSE-

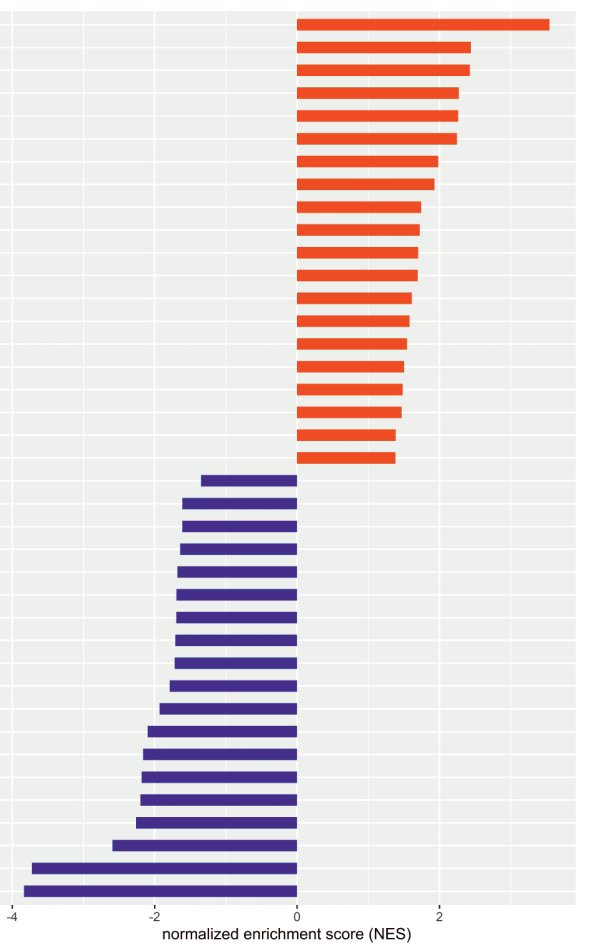

D CON/ Static vs AZM/ Static Gene sets correlated:

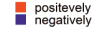

HALLMARK OXIDATIVE PHOSPHORYLATION HALIMARK_CHOLESTEROL_HOMEOSTASISHALLMARK_MTORC1_SIGNALING HALLMARK PROTEIN_SECRETION -

HALLMARK MYC TARGETS V1HALLMARK_PIIK_AKT_MTOR_SIGNALING HALLMARK_FATTY_ACID_METABOLISM -

HALLMARK ADIPOGENESIS HALLMARK P53 PATHWAY -

HALLMARK_ESTROGEN_RESPONSE_LATE HALLMARK PEROXISOME-

HALLMARK UV RESPONSE UP -

HALLMARK_BILE_ACID_METABOLISM HALLMARK_HEME_METABOLISM HALLMARK KRAS SIGNALING DN \%

0
0
0
0

0
$\Phi$
$\Xi$ HALLMARK_HYPOXIA HALLMARK ESTROGEN RESPONSE EARLY HALLMARK_INFLAMMATORY_RESPONSE HALLMARK_KRAS_SIGNALING UPHALLMARK_COAGULATIONHALLMARK_TNFA_SIGNALING_VIA_NFKBHALLMARK_ILE_JAK_STAT3_SIGNALING HALLMARK_MITOTIC_SPINDLE HALLMARK TGF BETA SIGNALINGHALLMARK_ANGIOGENESIS HALLMARK_APICAL_JUNCTIONHALLMARK_ G2M_CHECKPOINT HALLMARK_E2F_TARGETS HALLMARK_UV_RESPONSE_DN HALLMARK EPITHELIAL_MESENCHYMAL_TRANSTTON-

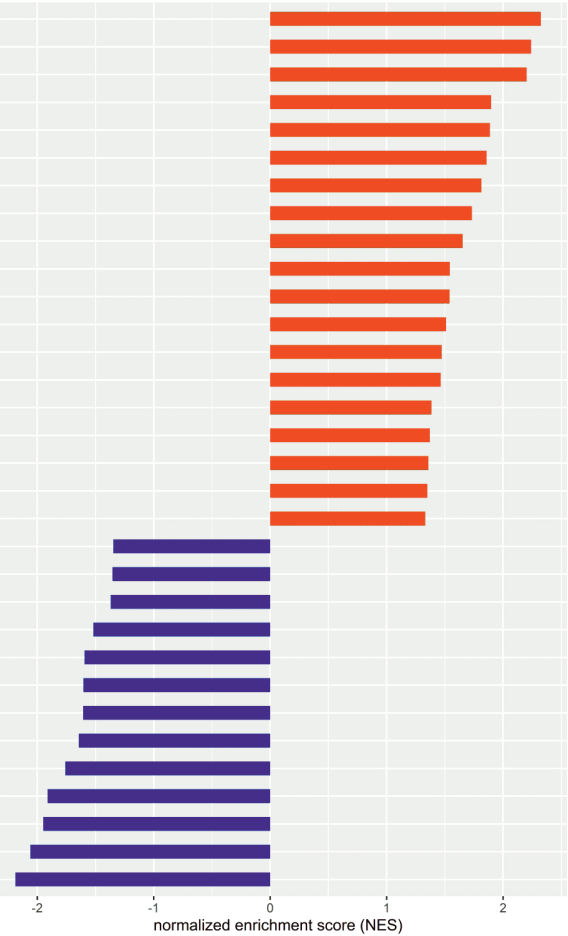

C) CON/Stress vs AZM/

Stress;

D) CON/Static vs AZM/Static; 
E

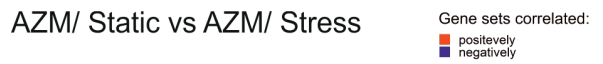

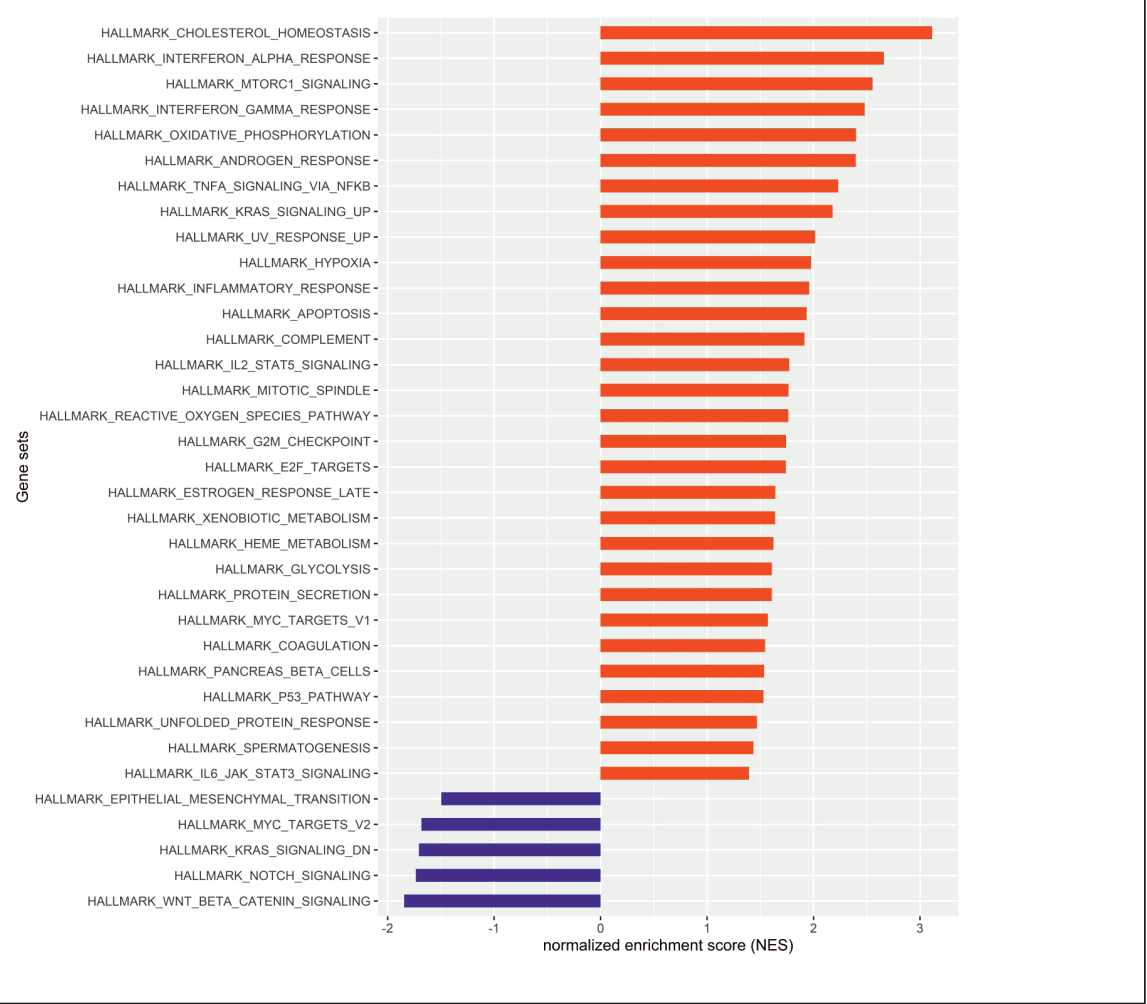

E) AZM/Static vs. AZM/ Stress. Positive correlations are reflected as high normalized enrichment scores (NES).

Tab. 1: List of over-represented gene ontology (GO) groups in A) CON/Static vs CON/Stress and B) CON/Static vs AZM/Stress pretreated VA10 cell layers

RNA sequencing data was uploaded into the Panther gene ontology database. Only genes with a q-value of $\leq 0.05$ and a fold change of $\geq 2$ were uploaded. The 33 Panther GO categories with the highest fold enrichment are shown.

\begin{tabular}{|l|l|l|}
\hline A) CON/Static vs CON/Stress & Fold enrichment & Raw P-value \\
\hline GO biological process complete & 65.82 & $6.42 \mathrm{E}-05$ \\
\hline regulation of type III interferon production (GO:0034344) & 32.91 & $2.61 \mathrm{E}-04$ \\
\hline wound healing involved in inflammatory response (GO:0002246) & 32.91 & $2.61 \mathrm{E}-04$ \\
\hline neural crest cell migration involved in autonomic nervous system development (GO:1901166) & $2.61 \mathrm{E}-04$ \\
\hline ISG15-protein conjugation (GO:0032020) & 32.91 & $2.61 \mathrm{E}-04$ \\
\hline detection of virus (GO:0009597) & 32.91 & $2.61 \mathrm{E}-04$ \\
\hline cytoplasmic pattern recognition receptor signaling pathway in response to virus (GO:0039528) & 32.91 & $3.16 \mathrm{E}-05$ \\
\hline regulation of ribonuclease activity (GO:0060700) & 29.25 & $3.69 \mathrm{E}-04$ \\
\hline inflammatory response to wounding (GO:0090594) & 28.21 & $6.61 \mathrm{E}-04$ \\
\hline positive regulation of RIG-I signaling pathway (GO:1900246) & 21.94 & $6.61 \mathrm{E}-04$ \\
\hline $\begin{array}{l}\text { positive regulation of blood vessel endothelial cell proliferation involved in sprouting } \\
\text { angiogenesis (GO:1903589) }\end{array}$ & 21.94 & $9.38 \mathrm{E}-06$ \\
\hline positive regulation of T cell apoptotic process (GO:0070234) & 21.94 & $\mathbf{2 1 . 6 1}$ \\
\hline type I interferon signaling pathway (GO:0060337) & 21.61 & $\mathbf{5}$ \\
\hline cellular response to type I interferon (GO:0071357) & 21.03 & $5.61 \mathrm{E}-21$ \\
\hline response to type I interferon (GO:0034340) & $1.19 \mathrm{E}-21$ \\
\hline
\end{tabular}




\begin{tabular}{|c|c|c|}
\hline \multicolumn{3}{|l|}{ A) CON/Static vs CON/Stress } \\
\hline GO biological process complete & Fold enrichment & Raw P-value \\
\hline negative regulation of viral genome replication (GO:0045071) & 20.08 & $6.47 \mathrm{E}-17$ \\
\hline response to interferon-alpha (GO:0035455) & 19.20 & 3.04E-07 \\
\hline positive regulation of T cell differentiation in thymus (GO:0033089) & 17.95 & $1.07 \mathrm{E}-03$ \\
\hline positive regulation of lymphocyte apoptotic process (GO:0070230) & 17.32 & $2.45 \mathrm{E}-05$ \\
\hline response to interferon-beta (GO:0035456) & 15.89 & 9.06E-07 \\
\hline negative regulation of viral life cycle (GO:1903901) & 15.86 & $5.89 \mathrm{E}-17$ \\
\hline positive regulation of interferon-alpha production (GO:0032727) & 15.80 & 5.76E-06 \\
\hline regulation of interferon-alpha production (GO:0032647) & 14.86 & $1.33 \mathrm{E}-06$ \\
\hline cellular response to exogenous dsRNA (GO:0071360) & 14.63 & 2.91E-04 \\
\hline positive regulation of monocyte chemotaxis (GO:0090026) & 14.63 & 2.91E-04 \\
\hline negative regulation of viral process (GO:0048525) & 14.34 & $1.01 \mathrm{E}-17$ \\
\hline defense response to virus (GO:0051607) & 13.50 & $1.65 \mathrm{E}-30$ \\
\hline regulation of viral genome replication (GO:0045069) & 13.30 & $5.89 \mathrm{E}-15$ \\
\hline cellular response to interferon-beta (GO:0035458) & 13.16 & 4.13E-04 \\
\hline positive regulation of cell migration involved in sprouting angiogenesis (GO:0090050) & 12.54 & 4.86E-04 \\
\hline regulation of nuclease activity (GO:0032069) & 11.97 & 5.67E-04 \\
\hline fibrinolysis (GO:0042730) & 11.97 & 5.67E-04 \\
\hline pyrimidine nucleoside catabolic process (GO:0046135) & 11.45 & $6.58 \mathrm{E}-04$ \\
\hline cellular response to dsRNA (GO:0071359) & 11.45 & $6.58 \mathrm{E}-04$ \\
\hline
\end{tabular}

\begin{tabular}{|c|c|c|}
\hline \multicolumn{3}{|l|}{ B) CON/Static vs AZM/Stress } \\
\hline GO biological process complete & Fold enrichment & Raw P value \\
\hline cholesterol biosynthetic process via lathosterol (GO:0033490) & 21.63 & 1.19E-03 \\
\hline cholesterol biosynthetic process via desmosterol (GO:0033489) & 21.63 & 1.19E-03 \\
\hline smooth muscle adaptation (GO:0014805) & 21.63 & 1.19E-03 \\
\hline foam cell differentiation (GO:0090077) & 16.48 & $3.42 \mathrm{E}-04$ \\
\hline macrophage derived foam cell differentiation (GO:0010742) & 16.48 & $3.42 \mathrm{E}-04$ \\
\hline low-density lipoprotein particle clearance (GO:0034383) & 13.22 & 1.11E-08 \\
\hline positive regulation of ryanodine-sensitive calcium-release channel activity (GO:0060316) & 12.82 & 7.02E-04 \\
\hline skin morphogenesis (GO:0043589) & 12.82 & 7.02E-04 \\
\hline chemical homeostasis within a tissue (GO:0048875) & 11.09 & $2.48 \mathrm{E}-04$ \\
\hline cholesterol biosynthetic process (GO:0006695) & 10.99 & $4.63 \mathrm{E}-11$ \\
\hline sterol biosynthetic process (GO:0016126) & 10.82 & $3.51 \mathrm{E}-12$ \\
\hline secondary alcohol biosynthetic process (GO:1902653) & 10.73 & $6.15 \mathrm{E}-11$ \\
\hline membrane raft assembly (GO:0001765) & 10.49 & 1.27E-03 \\
\hline $\mathrm{N}$-acetylneuraminate metabolic process (GO:0006054) & 10.49 & 1.27E-03 \\
\hline surfactant homeostasis (GO:0043129) & 10.49 & 1.27E-03 \\
\hline regulation of cholesterol biosynthetic process (GO:0045540) & 10.06 & $5.10 \mathrm{E}-10$ \\
\hline regulation of sterol biosynthetic process (GO:0106118) & 10.06 & $5.10 \mathrm{E}-10$ \\
\hline negative regulation of protein homooligomerization (GO:0032463) & 9.61 & $1.65 \mathrm{E}-03$ \\
\hline sequestering of metal ion (GO:0051238) & 9.61 & $1.65 \mathrm{E}-03$ \\
\hline hemidesmosome assembly (GO:0031581) & 9.61 & $1.65 \mathrm{E}-03$ \\
\hline phagosome acidification (GO:0090383) & 9.27 & 2.72E-06 \\
\hline
\end{tabular}




\begin{tabular}{|l|l|l|}
\hline B) CON/Static vs AZM/Stress & Fold enrichment & Raw P value \\
\hline GO biological process complete & 9.01 & $5.43 \mathrm{E}-04$ \\
\hline intracellular cholesterol transport (GO:0032367) & 8.87 & $1.28 \mathrm{E}-05$ \\
\hline regulation of water loss via skin (GO:0033561) & 8.78 & $4.79 \mathrm{E}-05$ \\
\hline establishment of skin barrier (GO:0061436) & 8.76 & $2.16 \mathrm{E}-10$ \\
\hline regulation of cholesterol metabolic process (GO:0090181) & 8.65 & $1.80 \mathrm{E}-04$ \\
\hline ceramide catabolic process (GO:0046514) & 8.48 & $6.83 \mathrm{E}-04$ \\
\hline intracellular sterol transport (GO:0032366) & 8.24 & $1.01 \mathrm{E}-17$ \\
\hline cornification (GO:0070268) & 8.01 & $2.30 \mathrm{E}-06$ \\
\hline transferrin transport (GO:0033572) & 8.01 & $8.49 \mathrm{E}-04$ \\
\hline positive regulation of steroid biosynthetic process (GO:0010893) & 7.74 & $9.57 \mathrm{E}-07$ \\
\hline plasma lipoprotein particle clearance (GO:0034381) & 7.59 & $1.04 \mathrm{E}-03$ \\
\hline positive regulation of histone deacetylation (GO:0031065) & 7.52 & $3.41 \mathrm{E}-04$ \\
\hline cholesterol efflux (GO:0033344) & & \\
\hline
\end{tabular}

Tab. 2: Genes of the GO biological process "Response to type I interferon" differentially expressed in the CON/Stress vs AZM/Stress pretreated VA10 cell layers RNA sequencing data was uploaded into the Panther gene ontology database. Only genes with a q-value of $\leq 0.05$ and a fold change of $\geq 2$ were uploaded.

\begin{tabular}{|c|c|c|c|}
\hline Mapped Ids & Gene name & CON & AZM \\
\hline & & \multicolumn{2}{|c|}{ Fold change } \\
\hline ENSG00000185507 & IRF7 & 21.81 & 13.43 \\
\hline ENSG00000172183 & ISG20 & 19.11 & 15.96 \\
\hline ENSG00000157601 & MX1 & 15.35 & 2.06 \\
\hline ENSG00000183486 & MX2 & 11.94 & 2.49 \\
\hline ENSG00000089127 & AC004551.1 & 11.18 & 3.70 \\
\hline ENSG00000101347 & SAMHD1 & 10.37 & 0.12 \\
\hline ENSG00000111335 & OAS2 & 9.71 & 2.19 \\
\hline ENSG00000130813 & C19orf66 & 9.56 & 1.60 \\
\hline ENSG00000134321 & RSAD2 & 8.92 & 4.99 \\
\hline ENSG00000185745 & IFIT1 & 8.33 & 5.18 \\
\hline ENSG00000067066 & SP100 & 7.81 & 1.34 \\
\hline ENSG00000187608 & ISG15 & 6.13 & 2.99 \\
\hline ENSG00000115415 & STAT1 & 5.25 & 1.80 \\
\hline ENSG00000119917 & IFIT3 & 4.73 & 5.42 \\
\hline ENSG00000111331 & OAS3 & 4.16 & 1.51 \\
\hline ENSG00000135114 & OASL & 3.96 & 1.21 \\
\hline ENSG00000068079 & IFI35 & 3.30 & 1.82 \\
\hline ENSG00000126709 & IFI6 & 3.09 & 2.35 \\
\hline ENSG00000165949 & IFI27 & 3.05 & 2.61 \\
\hline ENSG00000132530 & XAF1 & 2.88 & 1.35 \\
\hline ENSG00000185885 & IFITM1 & 2.63 & 3.02 \\
\hline ENSG00000172936 & MYD88 & 2.52 & 1.29 \\
\hline ENSG00000119922 & IFIT2 & 1.95 & 3.28 \\
\hline
\end{tabular}

gene sets was considerably higher for the $\mathrm{CON} / \mathrm{Static}$ cells, i.e., 3.44 compared to 2.27 in that case (Fig. S2 ${ }^{1}$ ).

When comparing RNA sequencing of CON/Stress vs AZM/ Stress, we observed that inflammation related pathways were significantly negatively correlated (Fig. 3C). Several of the pathways that were upregulated because of stress were downregulated when cells were AZM pre-treated (Fig. 3A,C).

The effect of AZM treatment alone was also explored. The positively correlated gene sets were not associated with inflammation, but there was a high negative correlation to inflammatory response and $\mathrm{TNF} \alpha$ signaling via NFKB (Fig. 3D).

Lastly, we compared AZM/Static vs AZM/Stress. The inflammatory response was present, but the NES was considerably lower compared to CON/Static vs CON/Stress. Also, fewer inflammatory related gene sets were significantly enriched (Fig. 3E).

Exploring the IFN $\alpha$ pathway, we set up a heat map showing 24 of the most significantly differentially expressed genes in the pathway (Fig. S3 ${ }^{1}$ ). This clearly shows the attenuating effect of AZM on gene expression.

To further investigate the gene enrichment patterns of the two conditions, we uploaded statistically significantly $(\mathrm{P} \leq 0.05)$ differentially expressed genes with at least two-fold upregulation into the PANTHER gene ontology (GO) classification system (Mi et al., 2017). The outcome was two very different GO biological process analyses. Cyclical stress of untreated cell layers (CON/ Stress) resulted in enrichment of inflammation-linked GO categories (Tab. 1A). Cyclically stressing AZM pre-treated cells (AZM/ Stress) resulted in the top enriched GO categories being associated with lipid metabolism and skin barrier (Tab. 1B).

As the GO analyses indicated prominent type-I interferon pathway activity (fold enrichment of 21.61 and raw P-value of 5.6 $\mathrm{E}^{-21}$ ) in the CON/Stress cell layer, we looked up the genes that were enriched in our gene set and saw that the genes involved were less differentially expressed in the AZM/Stress setting (Tab. 2). AZM-mediated immunomodulation was also detected when important immunity markers (cytokines/chemokines, toll-like receptors, matrix 
metalloproteases and TNF super family) were tested in the datasets of both conditions (Tab. 3). Only significantly differentially expressed genes are shown $(\mathrm{P} \leq 0.05)$. CON/Stress cell layers tended to show considerable differential expression of selected immune genes, whereas AZM/Stress cell layers showed fewer differentially expressed genes (Tab. 3).

\subsection{AZM attenuates stress-induced inflammatory response in bronchial epithelial cell layers - immunostaining analysis}

As the gene enrichment analysis showed high enrichment scores for TNF $\alpha$ signaling via $\mathrm{NFKB}$, we analyzed the effects of AZM-pretreatment on NFKB localization in VA10 cells. Cell layers were immunostained for $\mathrm{NFKB}$ and viewed using a confocal microscope. Using the co-localization feature of the Olympus fluoview software, we observed that NFkB translocation to the nucleus was increased in CON/Stress cell layers, compared to $\mathrm{CON} /$ Static cell layers (Fig. 4A, upper). Compared to CON/ Stress cell layers, the NFKB nuclear translocation was attenuated in AZM/Stress conditions (Fig. 4A, lower).

As NFKB nucleus translocation is usually preceded by a breakdown of IKB, we investigated the expression of IKB. Western blotting revealed no changes in IкB protein level, indicating non-canonical NFKB pathway activation (Sun, 2017) (Fig. S4 ${ }^{1}$ ).

On transcriptional level, we had seen that the expression of pro-inflammatory cytokine CXCL8 was decreased by AZM pre-treatment (AZM/Static), but significantly increased upon mechanically stressing the cells (CON/Stress). The combined effect of AZM pre-treatment and mechanically stressing the cells (AZM/Stress) resulted in non-significant changes (Fig. 4B). This was substantiated on a protein level by detection of IL-8 release by ELISA, which showed the same pattern as the gene expression (Fig. 4C).

\subsection{YKL-40 is modulated in both cyclically stressed and $A Z M$ treated bronchial lung cell layers}

As YKL-40 is an emerging inflammatory marker (Dela Cruz et al., 2012; Libreros et al., 2013) that has been implicated in immunomodulation (Kastrup, 2012; Ling and Recklies, 2004) and tissue remodeling (Lee et al., 2011), and as a follow up to our previous study (Joelsson et al., 2019) showing increased expression of YKL-40 due to mechanical stress in bronchial cell layers, we analyzed the effects of AZM pre-treatment on YKL-40. YKL-40 immunofluorescent staining was increased upon mechanical stress in VA10 cell layers (CON/Stress) compared to CON/Static (Fig. 5A, upper). AZM pretreatment also increased YKL-40 protein staining (AZM/Static); this was not further increased by mechanical stress (AZM/Stress) (Fig. 5A, lower). Pixel intensity quantifications are shown in Figure $\mathrm{S} 5^{1}$. In line, Western blots in VA10 ALI cultured cells showed an increase in YKL-40 protein in CON/Stress compared to CON/Static conditions, as we had shown previously (Joelsson et al., 2019). The increase in YKL-40 protein was more pronounced in AZM/Static cells with no further increase in AZM/Stress cells (Fig. 5B and Fig. S6 ${ }^{1}$ ). Immunohistochemical staining of YKL-40 in untreated cells, and in AZM pre-treated cells, showed an increase
Tab. 3: Genes related to the immune response differentially expressed in the CON/Stress vs AZM/Stress pretreated VA10 cell layers

RNA sequencing data was uploaded into the Panther gene ontology database. Only genes with a q-value of $\leq 0.05$ and a fold change of $\geq 2$ were uploaded.

\begin{tabular}{|c|c|c|}
\hline CON/Static vs CON/Stress & \multicolumn{2}{|c|}{ CON/Static vs AZM/Stress } \\
\hline \multicolumn{3}{|c|}{ Cytokines/Chemokines } \\
\hline CXCL11 & CXCL14 & \\
\hline CXCL10 & CXCL17 & \\
\hline CXCL9 & IL1RN & \\
\hline CXCL16 & IL1B & \\
\hline CXCL17 & IL18 & \\
\hline CXCL1 & IL7R & \\
\hline CXCL5 & IL6ST & \\
\hline \multicolumn{3}{|l|}{ IL36G } \\
\hline \multicolumn{3}{|l|}{ IL1RN } \\
\hline \multicolumn{3}{|l|}{ IL1A } \\
\hline \multicolumn{3}{|l|}{ IL1B } \\
\hline \multicolumn{3}{|l|}{ IL22RA1 } \\
\hline \multicolumn{3}{|l|}{ IL18 } \\
\hline \multicolumn{3}{|l|}{ IL20RB } \\
\hline \multicolumn{3}{|l|}{ IL1R1 } \\
\hline \multicolumn{3}{|l|}{ IL1RL1 } \\
\hline \multicolumn{3}{|l|}{ IL20RA } \\
\hline \multicolumn{3}{|l|}{ IL7 } \\
\hline \multicolumn{3}{|c|}{ Toll-like receptors } \\
\hline \multicolumn{3}{|l|}{ TLR3 } \\
\hline \multicolumn{3}{|c|}{ Matrix metalloproteases - Inflammatory mediators } \\
\hline MMP10 & MMP7 & \\
\hline MMP13 & MMP28 & \\
\hline \multicolumn{3}{|l|}{ MMP3 } \\
\hline \multicolumn{3}{|l|}{ MMP2 } \\
\hline \multicolumn{3}{|l|}{ MMP14 } \\
\hline \multicolumn{3}{|l|}{ MMP15 } \\
\hline \multicolumn{3}{|l|}{ MMP7 } \\
\hline TNFSF13B & TNFAIP2 & \\
\hline TNFSF10 & TNFSF14 & \\
\hline TNFRSF10A & TNFRSF21 & \\
\hline \multicolumn{3}{|l|}{ TNFAIP1 } \\
\hline \multicolumn{3}{|l|}{ TNFRSF21 } \\
\hline TNFRSF10C & & \\
\hline
\end{tabular}

Log2 of Fold change

4


A

DAPI

NFKB

B

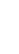
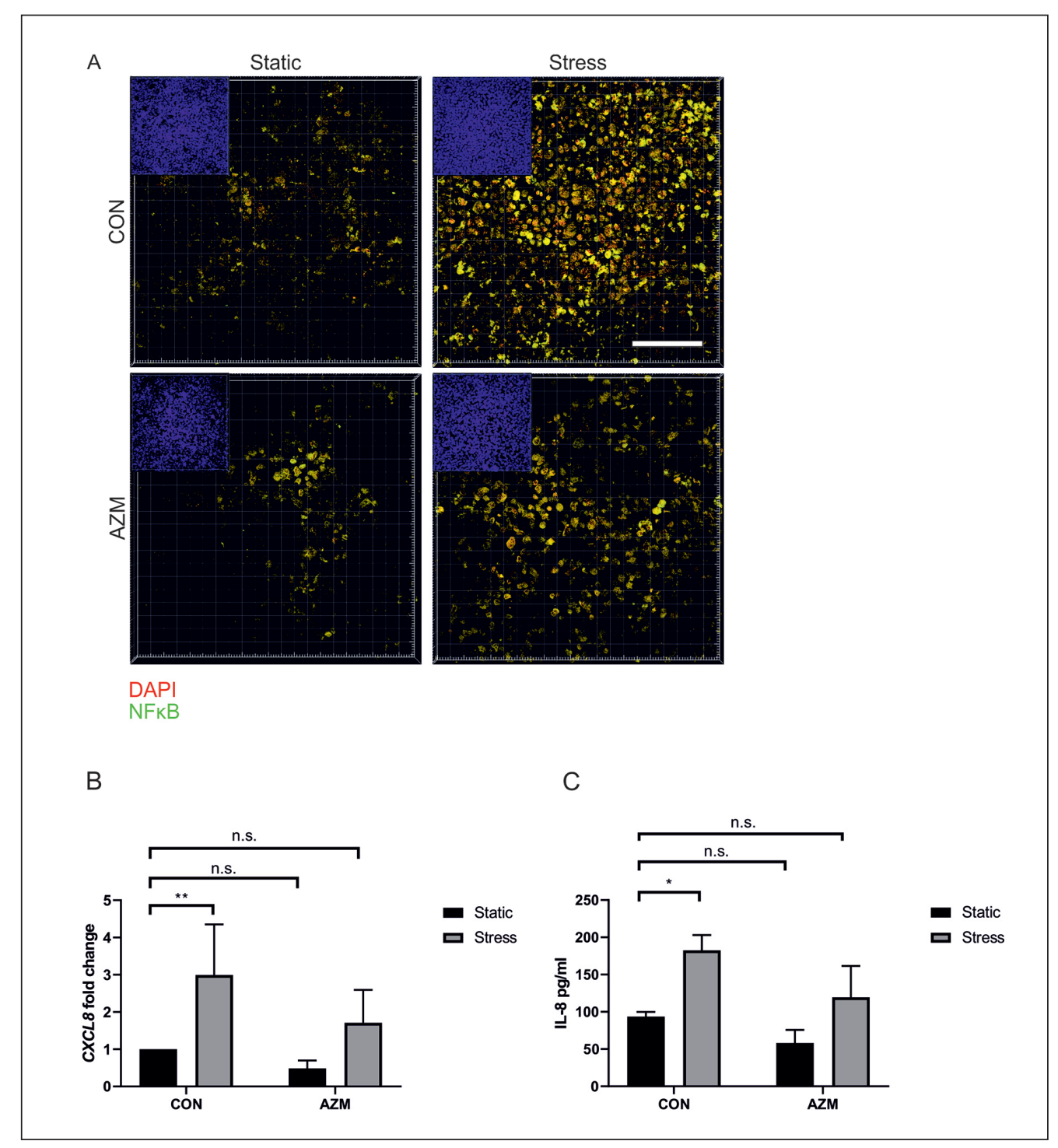

\section{.}

in YKL-40 expression along with a thickening of the cell layer (Fig. 5D), as seen in AZM treated cell layers before (Arason et al., 2019).

The expression of CHI3L1 (gene for YKL-40) increased in $\mathrm{CON} /$ Stress as well as AZM/Static cells (Fig. 5C). However, in comparison, the gene expression in AZM/Stress cells was much higher, indicating a co-operative effect. CHI3L1 differential expression was confirmed by RNA sequencing. Expression was increased 1.8-fold in CON/Stress versus CON/Static conditions and 10.2-fold in AZM/Stress versus CON/Static conditions (Fig 5E).

\section{Discussion}

Clinically, barrier failure of the epithelium is associated with inflammation and excessive cytokine signaling, aggravating the clinical symptoms of the patient, as immune cells from the surrounding
Fig. 4: Azithromycin pretreatment attenuates stress-induced inflammatory response in VA10 bronchial cell layers

ALI-cultured VA10 cell layers with/without AZM treatment (CON/AZM) in static or stress conditions (Static/Stress) for 21 days.

A) Confocal immunofluorescent images stained for NFkB translocation to DAPI-stained nuclei. Only co-localizations of DAPI and NFkB are shown using the co-localization feature of the Olympus fluoview software; z-stacks were merged; insets show DAPI-stained nuclei. Representative images of 3 independent experiments $(\mathrm{N}=3)$. Scale bar is $100 \mu \mathrm{m}$. B) CXCL8 expression $\left(\mathrm{N}=5 ;{ }^{* *}, \mathrm{P} \leq 0.01\right)$ and C) IL-8 protein measured by ELISA $\left(\mathrm{N}=3,{ }^{*}, \mathrm{P} \leq 0.05\right)$. blood vessels are overly active, resulting in excessive inflammatory responses (Slutsky and Ranieri, 2013). The immunomodulatory effects of macrolides are gaining interest in this respect (Zimmermann et al., 2018). AZM in particular has been linked to reducing the production of pro-inflammatory cytokines and promoting the resolution of chronic inflammation (Cramer et al., 2017).

Alveolar and bronchial lung cell layers subjected to CPAD stress showed a disrupted barrier, characterized by loss of gridlike formation with aggregated and disorganized actin fibers along with a reduction of important junctional proteins, i.e., E-cadherin. We observed that upon pre-treatment with AZM, barrier integrity was maintained during cyclical stress in the CPAD. An increase in vesicle and lamellar body formations was seen when untreated cells were mechanically stressed. As expected (Arason et al., 2019), AZM pre-treatment already increased lamellar body formation, which is associated with barrier integrity in the epidermis. When AZM pre-treated cells then were stressed in the CPAD, an 


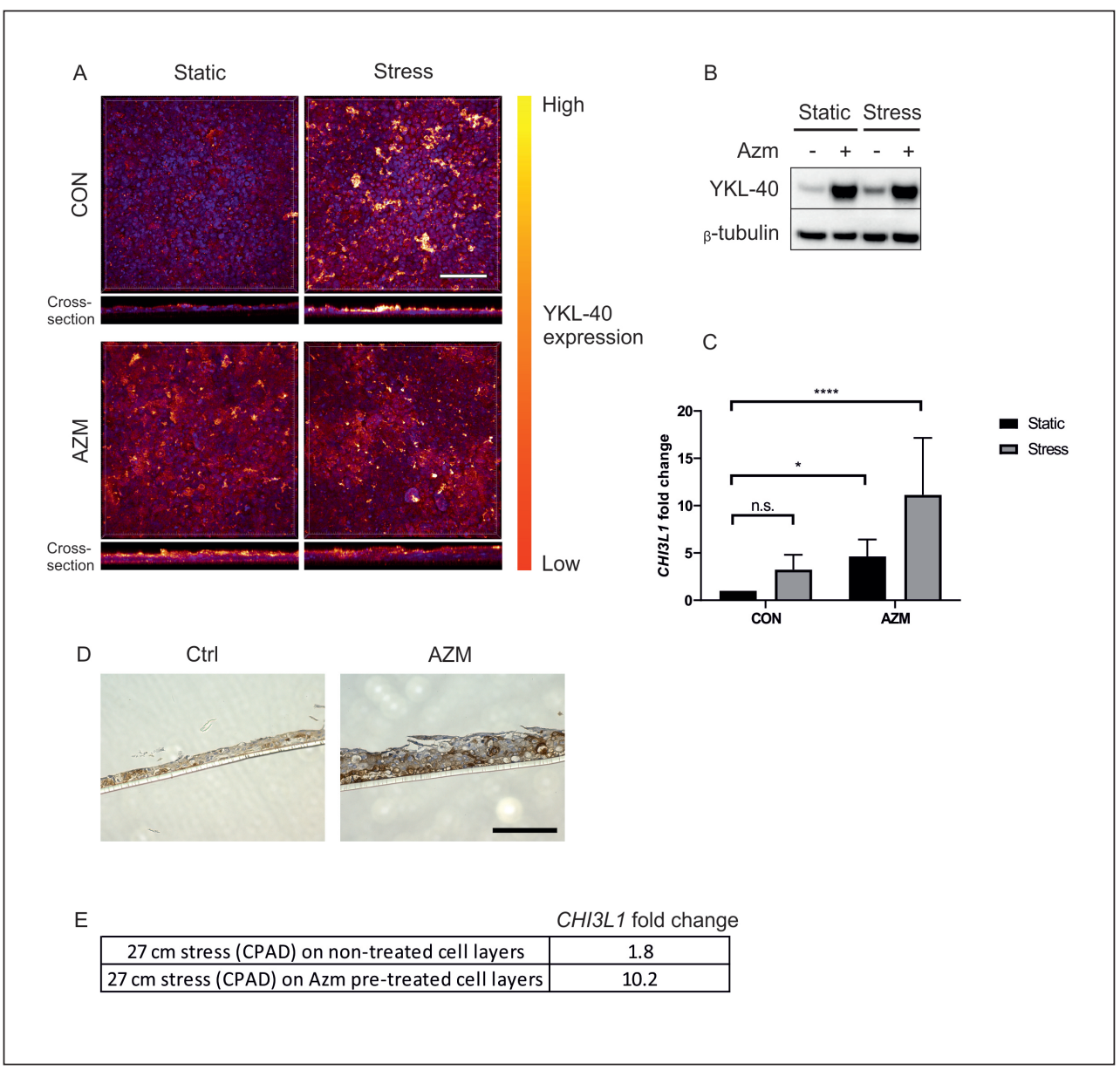

Fig. 5: YKL-40 expression is modulated in both stressinduced and azithromycintreated bronchial cell layers ALI-cultured VA10 cell layers with/without AZM treatment (CON/AZM) in static or stress conditions (Static/Stress) for 21 days. A) Confocal images stained for YKL-40. Representative images of 3 independent experiments are shown $(\mathrm{N}=3)$. B) Western blot analysis for YKL-40. Representative images of 3 independent experiments are shown $(\mathrm{N}=3)$. $\beta$-tubulin shown as house-keeping gene. C) Gene expression of CHI3L1 determined by RT-qPCR ( $\mathrm{N}=9$; *, $\mathrm{P} \leq 0.05 ;{ }^{* * *}, \mathrm{P} \leq 0.0001$ ). D) Immunohistochemical staining of cell layers with YKL-40; counterstained with hematoxylin. Representative images of 3 independent experiments are shown. Scale bar is $100 \mu \mathrm{m}$. E) Gene expression of CHI3L1 determined by RNA sequencing.

exaggerated lamellar body formation response was observed, indicating that lamellar body formation under pressure might be a protective response to injury. With the addition of AZM, this response was augmented to the extent that a functional barrier was maintained.

Importantly, we saw that cyclical stress induces SFPB expression both in untreated VA10 and hAELVi cell lines. In line, we reported earlier that SFPB gene expression both in untreated VA10 cells in response to stress in the CPAD (Joelsson et al., 2019). For the hAELVi cell line, this could indicate a sub-population of alveolar type II cells within the cell culture. In these cells, the AZM pre-treatment resulted in slightly increased SFPB expression, possibly due to activation of these type II cells, but no further increase was detected after cyclically stressing the cells. Surfactant production has been linked to prognosis in pulmonary diseases (Delgado et al., 2015; Han and Mallampalli, 2015). As no further surfactant production was seen in AZM-treated mechanically stressed cells, we postulate that this might indicate a protective mechanism where surfactant production is not as readily triggered by injury in AZM-treated cells.

Upon analyzing RNA sequencing data of the bronchial VA10 cells, where we compared the gene expression profiles of all the conditions tested, we found that when stress was the only fac- tor, GSEA showed a strong positive correlation to many immune-related gene sets. However, GSEA in AZM/Stress cell layers showed considerably lower NES in the same immune related gene sets, indicating an attenuated inflammation response. When we compared CON/Stress cells with AZM/Stress cells, we observed that AZM treatment resulted in negative correlation with a number of inflammation related pathways. In fact, inflammatory response gene sets, along with TNF $\alpha$ signaling via NFKB, were negatively correlated when AZM pre-treatment was the only factor. A similar effect was observed when differentially expressed genes were analyzed by PANTHER, another GO database. Overrepresented inflammation and immune related GO categories seen in CON/Stress cells were not seen in AZM/Stress cells, being replaced by fatty acid metabolism- and barrier-related GO categories. When immune markers, i.e., cytokines/chemokines, toll-like receptors, matrix metalloproteases and TNF super family were checked in the RNA sequencing data, the number of genes significantly differentially expressed because of cyclical stress was markedly reduced when cells had been pre-treated with AZM, indicating a dampening of the immune response.

AZM pre-treatment of bronchial lung epithelial cells resulted in significant downregulation of TNF and CXCL8, key effectors of inflammatory response (Lawrence, 2009). In this work, we 
show that CPAD mechanical stressing of bronchial epithelial cells results in increased $\mathrm{NFKB}$ localization to the nucleus and an increase in IL8 expression on the RNA and protein level. Conversely, pre-treatment with AZM attenuated the NFKB/nucleus co-localization and IL8 expression in CPAD stressed cells. When AZM pre-treated cells were stressed, we no longer saw significant increases in IL8 expression as seen in the CON/Stress cells. We did not observe reduced levels of IkB (Fig. S4 ${ }^{1}$ ), indicating that the non-canonical pathway is activated, in which NFKB translocation does not depend on IKB breakdown (Sun, 2017).

As barrier failure and an inappropriate inflammatory response are connected, and there is likely remodeling of tissue in response to injury (Lee et al., 2011), we also investigated the inflammation-related marker YKL-40 in our model. YKL40 protein was increased comparably both in CON/Stress and AZM/Static conditions versus CON/Static; whereas there was no further increase of YKL40 in AZM/Stress versus AZM/Static conditions. The AZM-induced YKL-40 protein was evenly distributed, whereas YKL-40 in the CON/Stress condition showed a more erratic pattern. The YKL-40 protein data were confirmed by gene expression data. The mechanisms of YKL-40 are still being deciphered. The data presented in this study support the indications of a cytoprotective role for this molecule, as has been suggested before (Majewski et al., 2019).

We have previously used TEER as a marker for epithelial barrier in ALI culture (Joelsson et al., 2019). In the current study, TEER did not decrease after stressing the cells. Indeed, after stressing the cells, TEER showed a high variation between measurements. Thus, TEER was an unreliable marker for barrier integrity in the CPAD condition. This might be explained by the mechanical effects on the cell layer, causing formation of cell aggregates in some instances and tears in the layer in others.

The hAELVi cell line is characterized as alveolar type I, but, interestingly, it showed expression of surfactant protein $B$ in the CPAD, which is a characteristic of type II cells. This phenotype was induced in the cell line during mechanical stress or by AZM treatment. We aim to follow this up as well as to compare the effect of AZM on gene and protein levels to that on VA10 cells in future studies.

The CPAD aims to reduce and replace animal experiments by modeling mechanical ventilation induced lung injury in human cells. This study confirms the relevance of the model as the clinical effects of AZM can be reproduced and investigated mechanistically in the CPAD. It is desirable that alternatives to animal experiments also aim to replace animal-derived components such as antibodies from ascites fluid, with non-animal alternatives. This can be challenging when the composition of media or the origin of components is not disclosed by the companies selling them. We will investigate whether substitutes are available in future studies.

Long-term use of AZM has been widely practiced in clinical treatment and in clinical trials of patients with serious chronic lung diseases and ARDS without full understanding of its pharmacologic mechanisms (Kawamura et al., 2016). It even has been proposed to be the "Holy Grail" to prevent exacerbation in chronic respiratory diseases (Welte, 2019) although the antibiotic aspect of AZM can lead to increased macrolide resistance (Taylor et al., 2019). The information provided in this paper may be an important step towards understanding the biological pathways that underlie the effects of AZM and might be utilized to develop drugs without antibacterial activity that influence barrier integrity and modulate inflammatory response. These could be screened and characterized in the CPAD model and compared to AZM to reduce and replace animal experiments.

Overall, the findings of this study show that AZM pre-treatment maintains barrier integrity in mechanically stressed bronchial and alveolar cell layers and shows a robust anti-inflammatory modulation in bronchial cell layers.

\section{References}

Arason, A. J., Joelsson, J. P., Valdimarsdottir, B. et al. (2019). Azithromycin induces epidermal differentiation and multivesicular bodies in airway epithelia. Respir Res 20, 129. doi:10. 1186/s12931-019-1101-3

Asgrimsson, V., Gudjonsson, T., Gudmundsson, G. H. et al. (2006). Novel effects of azithromycin on tight junction proteins in human airway epithelia. Antimicrob Agents Chemother 50, 1805-1812. doi:10.1128/aac.50.5.1805-1812.2006

Blondonnet, R., Constantin, J. M., Sapin, V. et al. (2016). A pathophysiologic approach to biomarkers in acute respiratory distress syndrome. Dis Markers 2016, 3501373. doi:10.1155/ 2016/3501373

Bray, N. L., Pimentel, H., Melsted, P. et al. (2016). Near-optimal probabilistic RNA-seq quantification. Nat Biotechnol 34, 525 527. doi:10.1038/nbt.3519

Champney, W. S. and Burdine, R. (1998). Azithromycin and clarithromycin inhibition of $50 \mathrm{~S}$ ribosomal subunit formation in Staphylococcus aureus cells. Curr Microbiol 36, 119-123. doi: 10.1007/s002849900290

Champney, W. S., Tober, C. L. and Burdine, R. (1998). A comparison of the inhibition of translation and 50S ribosomal subunit formation in staphylococcus aureus cells by nine different macrolide antibiotics. Curr Microbiol 37, 412-417. doi: 10.1007/s002849900402

Cigana, C., Nicolis, E., Pasetto, M. et al. (2006). Anti-inflammatory effects of azithromycin in cystic fibrosis airway epithelial cells. Biochem Biophys Res Commun 350, 977-982. doi:10.1016/j.bbrc.2006.09.132

Cramer, C. L., Patterson, A., Alchakaki, A. et al. (2017). Immunomodulatory indications of azithromycin in respiratory disease: A concise review for the clinician. Postgrad Med 129, 493-499. doi:10.1080/00325481.2017.1285677

Dela Cruz, C. S., Liu, W., He, C. H. et al. (2012). Chitinase 3-like-1 promotes Streptococcus pneumoniae killing and augments host tolerance to lung antibacterial responses. Cell Host Microbe 12, 34-46. doi:10.1016/j.chom.2012.05.017

Delgado, C., Krotzsch, E., Jimenez-Alvarez, L. A. et al. (2015). Serum surfactant protein D (SP-D) is a prognostic marker of poor outcome in patients with A/H1N1 virus infection. Lung 193, 25-30. doi:10.1007/s00408-014-9669-3

Gibson, P. G., Yang, I. A., Upham, J. W. et al. (2017). Effect of azithromycin on asthma exacerbations and quality of life in 
adults with persistent uncontrolled asthma (AMAZES): A randomised, double-blind, placebo-controlled trial. Lancet 390, 659-668. doi:10.1016/s0140-6736(17)31281-3

Gotfried, M. H. (2004). Macrolides for the treatment of chronic sinusitis, asthma, and COPD. Chest 125, 52S-60S; quiz 60S-61S. doi:10.1378/chest.125.2_suppl.52s

Halldorsson, S., Asgrimsson, V., Axelsson, I. et al. (2007). Differentiation potential of a basal epithelial cell line established from human bronchial explant. In Vitro Cell Dev Biol Anim 43, 283-289. doi:10.1007/s11626-007-9050-4

Halldorsson, S., Gudjonsson, T., Gottfredsson, M. et al. (2010). Azithromycin maintains airway epithelial integrity during Pseudomonas aeruginosa infection. Am J Respir Cell Mol Biol 42, 62-68. doi:10.1165/rcmb.2008-0357oc

Han, S. and Mallampalli, R. K. (2015). The role of surfactant in lung disease and host defense against pulmonary infections. Ann Am Thorac Soc 12, 765-774. doi:10.1513/annalsats. 201411-507fr

Hansen, J. L., Ippolito, J. A., Ban, N. et al. (2002). The structures of four macrolide antibiotics bound to the large ribosomal subunit. Mol Cell 10, 117-128. doi:10.1016/s1097-2765 (02)00570-1

Huh, D. D. (2015). A human breathing lung-on-a-chip. Ann Am Thorac Soc 12, Suppl 1, S42-44. doi:10.1513/AnnalsATS. 201410-442MG

Joelsson, J. P., Myszor, I. T., Arason, A. J. et al. (2019). Innovative in vitro method to study ventilator induced lung injury. ALTEX 36, 634-642. doi:10.14573/altex.1901182

Karadottir, H., Kulkarni, N. N., Gudjonsson, T. et al. (2015). Сyclic mechanical stretch down-regulates cathelicidin antimicrobial peptide expression and activates a pro-inflammatory response in human bronchial epithelial cells. PeerJ 3, e1483. doi: $10.7717 /$ peerj. 1483

Kastrup, J. (2012). Can YKL-40 be a new inflammatory biomarker in cardiovascular disease? Immunobiology 217, 483491. doi:10.1016/j.imbio.2011.04.007

Kawamura, K., Ichikado, K., Takaki, M. et al. (2016). Efficacy of azithromycin in sepsis-associated acute respiratory distress syndrome: A retrospective study and propensity score analysis. Springerplus 5, 1193. doi:10.1186/s40064-016-2866-1

Kawamura, K., Ichikado, K., Yasuda, Y. et al. (2017). Azithromycin for idiopathic acute exacerbation of idiopathic pulmonary fibrosis: A retrospective single-center study. BMC Pulm Med 17, 94. doi:10.1186/s12890-017-0437-z

Kuehn, A., Kletting, S., de Souza Carvalho-Wodarz, C. et al. (2016). Human alveolar epithelial cells expressing tight junctions to model the air-blood barrier. ALTEX 33, 251-260. doi: 10.14573/altex.1511131

Lawrence, T. (2009). The nuclear factor NF-кB pathway in inflammation. Cold Spring Harb Perspect Biol 1, a001651. doi:10. 1101/cshperspect.a001651

Lee, C. G., Da Silva, C. A., Dela Cruz, C. S. et al. (2011). Role of chitin and chitinase/chitinase-like proteins in inflammation, tissue remodeling, and injury. Annu Rev Physiol 73, 479-501. doi:10.1146/annurev-physiol-012110-142250

Liberzon, A., Birger, C., Thorvaldsdottir, H. et al. (2015). The mo- lecular signatures database (MSigDB) hallmark gene set collection. Cell Syst 1, 417-425. doi:10.1016/j.cels.2015.12.004

Libreros, S., Garcia-Areas, R. and Iragavarapu-Charyulu, V. (2013). CHI3L1 plays a role in cancer through enhanced production of pro-inflammatory/pro-tumorigenic and angiogenic factors. Immunol Res 57, 99-105. doi:10.1007/s12026-0138459-y

Ling, H. and Recklies, A. D. (2004). The chitinase 3-like protein human cartilage glycoprotein 39 inhibits cellular responses to the inflammatory cytokines interleukin-1 and tumour necrosis factor-alpha. Biochem J 380, 651-659. doi:10.1042/ bj20040099

Majewski, S., Tworek, D., Szewczyk, K. et al. (2019). Overexpression of chitotriosidase and YKL-40 in peripheral blood and sputum of healthy smokers and patients with chronic obstructive pulmonary disease. Int J Chron Obstruct Pulmon Dis 14, 1611-1631. doi:10.2147/copd.s184097

Meyer, N. J. and Christie, J. D. (2013). Genetic heterogeneity and risk of acute respiratory distress syndrome. Semin Respir Crit Care Med 34, 459-474. doi:10.1055/s-0033-1351121

Mi, H., Huang, X., Muruganujan, A. et al. (2017). Panther version 11: Expanded annotation data from gene ontology and reactome pathways, and data analysis tool enhancements. Nucleic Acids Res 45, D183-d189. doi:10.1093/nar/gkw1138

Mootha, V. K., Lindgren, C. M., Eriksson, K. F. et al. (2003). PGC-1 $\alpha$-responsive genes involved in oxidative phosphorylation are coordinately downregulated in human diabetes. Nat Genet 34, 267-273. doi:10.1038/ng1180

Naderi, N., Assayag, D., Mostafavi-Pour-Manshadi, S. M. et al. (2018). Long-term azithromycin therapy to reduce acute exacerbations in patients with severe chronic obstructive pulmonary disease. Respir Med 138, 129-136. doi:10.1016/j.rmed. 2018.03.035

Pimentel, H., Bray, N. L., Puente, S. et al. (2017). Differential analysis of RNA-seq incorporating quantification uncertainty. Nat Methods 14, 687-690. doi:10.1038/nmeth.4324

Pomares, X., Monton, C., Bullich, M. et al. (2018). Clinical and safety outcomes of long-term azithromycin therapy in severe COPD beyond the first year of treatment. Chest 153, 11251133. doi:10.1016/j.chest.2018.01.044

Principi, N., Blasi, F. and Esposito, S. (2015). Azithromycin use in patients with cystic fibrosis. Eur J Clin Microbiol Infect Dis 34, 1071-1079. doi:10.1007/s10096-015-2347-4

Ramos, F. L. and Criner, G. J. (2014). Use of long-term macrolide therapy in chronic obstructive pulmonary disease. Curr Opin Pulm Med 20, 153-158. doi:10.1097/mcp.0000000000000028

Ressler, B., Lee, R. T., Randell, S. H. et al. (2000). Molecular responses of rat tracheal epithelial cells to transmembrane pressure. Am J Physiol Lung Cell Mol Physiol 278, L1264-1272. doi:10.1152/ajplung.2000.278.6.11264

Shiomi, T., Tschumperlin, D. J., Park, J. A. et al. (2011). TNF- $\alpha-$ converting enzyme / A disintegrin and metalloprotease-17 mediates mechanotransduction in murine tracheal epithelial cells. Am J Respir Cell Mol Biol 45, 376-385. doi:10.1165/ rcmb.2010-0234oc

Slutsky, A. S. and Ranieri, V. M. (2013). Ventilator-induced lung 
injury. $N$ Engl $J$ Med 369, 2126-2136. doi:10.1056/nejmra 1208707

Subramanian, A., Tamayo, P., Mootha, V. K. et al. (2005). Gene set enrichment analysis: A knowledge-based approach for interpreting genome-wide expression profiles. Proc Natl Acad Sci U S A 102, 15545-15550. doi:10.1073/pnas.0506580102

Sun, S. C. (2017). The non-canonical NF-кB pathway in immunity and inflammation. Nat Rev Immunol 17, 545-558. doi: $10.1038 /$ nri.2017.52

Taylor, S. L., Leong, L. E. X., Mobegi, F. M. et al. (2019). Longterm azithromycin reduces haemophilus influenzae and increases antibiotic resistance in severe asthma. Am J Respir Crit Care Med 200, 309-317. doi:10.1164/rccm.201809-1739oc

Thompson, B. T., Chambers, R. C. and Liu, K. D. (2017). Acute respiratory distress syndrome. $N$ Engl J Med 377, 562-572. doi:10.1056/NEJMra1608077

Welte, T. (2019). Azithromycin: The holy grail to prevent exacerbations in chronic respiratory disease? Am J Respir Crit Care Med 200, 269-270. doi:10.1164/rccm.201903-0706ed

Yates, A., Akanni, W., Amode, M. R. et al. (2016). Ensembl 2016. Nucleic Acids Res 44, D710-716. doi:10.1093/nar/gkv1157

Yu, Q. and Li, M. (2017). Effects of transient receptor potential canonical 1 (TRPC1) on the mechanical stretch-induced expression of airway remodeling-associated factors in human bronchial epithelioid cells. J Biomech 51, 89-96. doi:10.1016/j. jbiomech.2016.12.002
Zhao, T., Liu, M., Gu, C. et al. (2014). Activation of c-Src tyrosine kinase mediated the degradation of occludin in ventilator-induced lung injury. Respir Res 15, 158. doi:10.1186/ s12931-014-0158-2

Zimmermann, P., Ziesenitz, V. C., Curtis, N. et al. (2018). The immunomodulatory effects of macrolides - A systematic review of the underlying mechanisms. Front Immunol 9, 302. doi:10.3389/fimmu.2018.00302

\section{Conflict of interest}

The authors declare that GHG, TG, FL and CPP work for and/or are shareholders in EpiEndo Pharmaceuticals.

\section{Funding}

This work was supported by the Icelandic Research Council (Rannís grant numbers: 195872-051) and the Landspitali University Hospital science fund.

\section{Acknowledgements}

We thank Johann Arnfinnsson and Paulina Cherek for their assistance in preparing TEM samples. We thank Bryndis Valdimarsdottir for her assistance with paraffin embedding. 